Original paper

\title{
Impact of COVID-19 infection on liver and alimentary tract: clinical insight
}

\author{
Taha Mohammad Hassanin'1, Hanaa Fathelbab', Hala Ibraheem', Sahar Hassany², Amr Zaghloul ${ }^{3}$, Assmaa Fathelbab \\ 'Endemic Medicine and Gastroenterology Department, Minia University Faculty of Medicine, Egypt \\ ${ }^{2}$ Tropical Medicine and Gastroenterology Department, Assiut University Faculty of Medicine, Egypt \\ ${ }^{3}$ Tropical Medicine and Gastroenterology Department, Sohag University Faculty of Medicine, Egypt \\ ${ }^{4}$ Radiology Department, Minia University Faculty of Medicine, Egypt
}

\begin{abstract}
Aim of the study: Our aim was to evaluate the impact of COVID-19 infection on the liver and alimentary tract. Material and methods: This is a retrospective multicenter study that was performed in non-intensive care units (ICU) at Minia, Assiut, and Sohag University Hospitals from March 1', 2020 to August 1st, 2020. The clinical characteristics of 1238 consecutively confirmed COVID-19 discharged cases were enrolled. Patients with respiratory distress were recorded as severe cases, while others were recorded as mild-moderate cases. Patients with $\geqslant 2 x$ upper limit of normal of alanine aminotransferase (ALT), aspartate aminotransferase (AST), or bilirubin were defined as patients with liver injury, while others were recorded as patients without liver injury.

Results: The severe group included 460 patients (37.2\%) while the mild-moderate group included 778 patients $(62.8 \%)$. Fever, white blood cell (WBC) and C-reactive protein (CRP) levels were significantly higher in the severe group $(p<0.05)$. The hepatic injury group included 296 patients $(23.9 \%)$ while the group without hepatic injury included 942 patients (76.1\%). Males were more likely to have liver injury $(p<0.05)$. Fever and abdominal pain were significantly higher in the hepatic injury group. Patients with liver injury had increased levels of WBCs, CRP and chest computed tomography (CT) score and had a longer hospital stay $(p<0.05)$. Chest CT score was a predictor of liver injury $(p<0.05)$.

Conclusions: Liver injury in non-ICU hospitalized COVID-19 patients is common but it is mild and has a good prognosis. Liver injury may be related to the degree of chest CT lesions.

Key words: hepatic injury, gastrointestinal symptoms, COVID-19, chest symptoms, chest CT lesions in COVID-19 patients.
\end{abstract}

\section{Address for correspondence}

Taha Mohammad Hassanin, MD, Assoc. Prof. of Endemic Medicine and Gastroenterology, Endemic Medicine and Gastroenterology Department, Minia University Faculty of Medicine, Egypt, e-mail: assemtaha2006@gmail.com

\section{Introduction}

COVID-19 is a respiratory illness caused by a novel coronavirus that was first identified in Wuhan, the capital city of China's Hubei Province, in December 2019 [1]. Initially it was referred to as the 2019 novel coronavirus that is caused by severe acute respiratory syndrome coronavirus 2 (SARS-CoV-2) [2]. Coronaviruses are a large family of RNA viruses that are known to cause illnesses ranging from the common cold to more severe diseases such as Middle East respiratory syndrome (MERS), severe acute respiratory syndrome (SARS) and severe organ dysfunction that can lead to death [3-5]. Most cases of COVID-19 appear to be mild, with the most common symptoms being fever (83-98\%), cough (46-82\%), myalgia or fatigue (11-44\%), and shortness of breath (31\%). Risk factors for more severe illness requiring hospitalization appear to be older age and having underlying chronic medical conditions such as diabetes, lung disease, and cardiovascular disease $[4,5]$. For more severe 
COVID-19 cases, the median time from first symptom onset to the development of shortness of breath and/or need for hospitalization ranged from 5 to 8 days [4-6]. Among hospitalized COVID-19 patients, it is reported that $5 \%$ to $26 \%$ have required admission to the intensive care unit $[4,6]$. The reported fatality rate for hospitalized COVID-19 patients has ranged from $1.4 \%$ to $15 \%$ [4-6]. The average incubation period for COVID-19 is 5 days but may range from 2 to 14 days, and potential asymptomatic infection has been reported $[5,7,8]$.

Of note for gastroenterologists, patients may complain of gastrointestinal symptoms such as nausea/ vomiting or diarrhea in up to $25 \%$ of patients $[5,9]$. The reported frequency of diarrhea among COVID-19 patients has varied from $2 \%$ to $33 \%$ and was one of the prominent symptoms reported in the United States $[9,10]$. Interestingly, the cell entry receptor ACE- 2 appears to mediate entry of SARS-CoV-2 and has been demonstrated to be highly expressed in small intestinal enterocytes [9]. COVID-19 virus has been detected in the stool of COVID-19 patients $[10,11]$. So, while COVID-19 appears to primarily spread through respiratory droplets and secretions, the gastrointestinal tract may be another potential route of infection, highlighting the importance of personal protective measures when dealing with the patient's personal hygiene. In addition to leukopenia (reported in $9-25 \%$ of cases) or leukocytosis (24-30\%), elevated alanine aminotransferase and aspartate aminotransferase have been observed in up to $37 \%$ of cases [5-7]. Another report from China also stated that around 10\% of COVID-19 patients had elevated total bilirubin levels [6]. Other studies reported elevated liver enzymes in a median of $15 \%$ and up to $58 \%$ of patients with COVID- 19 with aspartate aminotransferase (AST) and alanine aminotransferase (ALT) typically elevated 1-2 times the upper limit of normal $[12,13]$. Our aim was to evaluate the impact of COVID-19 infection on the liver and alimentary tract. As this infectious disease continues to spread, further clinical and epidemiological characteristics must be explored to improve our understanding of this pandemic.

\section{Material and methods}

This was a retrospective multicenter study conducted in non-ICU wards at Minia, Assiut, and Sohag University Hospitals from March $1^{\text {st }}, 2020$ to August $1^{\text {st }}$, 2020. A total of 1238 consecutive confirmed cases of COVID-19 patients were admitted and treated. The clinical criteria for diagnosis and discharge were as per the standards for "Diagnosis and Treatment Scheme of Egyptian Ministry of Health". All patients were di- agnosed after throat swab and examination of SARSCoV-2 RNA by reverse transcriptase polymerase chain reaction. This study was approved by the Ethics Committee of the local University Hospital.

\section{Data collection}

The medical records of 1238 patients were collected and examined by a trained research team from the Endemic Medicine and Gastroenterology Departments of the three university hospitals. Epidemiological, clinical and laboratory characteristics, as well as outcomes data, were gathered by the research team. All laboratory data were obtained on the day of admission then laboratory examination was conducted every other day. Total and differential leukocyte count, lymphocyte absolute value, erythrocyte sedimentation rate, serum ferritin, D-dimer test, blood urea, serum creatinine, lactic dehydrogenase (LDH), ALT, AST, and total bilirubin levels were routinely measured using standard methods.

Computed tomography (CT) chest scan was performed on all patients within 2-4 days after admission. Chest CT scores were assessed and assigned based on the area involved. There was a score of $0-5$ for each lobe, with a total possible score of $0-25$ (score $0=$ normal finding, score $1=<5 \%$ lung involvement, score $2=5-25 \%$, score 3 $=26-50 \%$, score $4=51-75 \%$, and score $5=>75 \%$ lung involvement) [14].

\section{Therapeutic policy}

All patients rested in bed and received supportive treatments including fluid supplementation and maintenance of electrolyte and acid-base homeostasis. Fever was treated with paracetamol \pm ibuprofen according to the patient's response. Antibiotics (azithromycin $500 \mathrm{mg}$ once daily for 6 days) were used if needed. Because there was no established antiviral treatment regimen, patients were treated with chloroquine $200 \mathrm{mg}$ three times daily (TDS)/10 days, and this decision was based on health care providers' discretion. Vital signs and finger oxygen saturation were closely monitored, and oxygen therapy through a nasal cannula was given to patients with hypoxemia.

Patients grouping: patients with respiratory rate $\geq 30$ breaths/min, resting oxygen saturation $\leq 93 \%$ or chest CT score $\geq 3$ were recorded as the severe group, while other patients were recorded as the mild-moderate group. Patients with elevated levels of ALT, AST, or bilirubin ( $\geq 2 \times$ upper level of normal [ULN]) were defined as having liver injury. 


\section{Statistical analysis}

Analysis of data was performed using SPSS software. Quantitative (continuous) variables were presented as mean and SD, and the paired sample $t$-test was used for comparison between variables, while qualitative (categorical) variables were presented as number and percent and the chi-squared or Fisher exact test was used for comparison between variables. $P$ values $<0.05$ were considered statistically significant.

\section{Results}

A total of 1238 cases with confirmed COVID-19 infection were included in this study. The severe group included $460(37.2 \%)$ patients while the mild-moderate group included $778(62.8 \%)$ patients. Comparison between the severe group and mild-moderate group showed that fever, white blood cell (WBC) and C-reactive protein (CRP) levels were significantly higher in the severe group (all $p$ values were $<0.05$ ). No significant differences were found between these two groups regarding the other clinical or laboratory features (Table 1). Among the 1238 included patients, there were 296 patients (23.9\%) with elevated ALT, AST, and/or bilirubin $\geq 2 \times$ ULN (group with hepatic injury), while the other 942 patients $(76.1 \%)$ were assigned as the group without hepatic injury. The clinical characteristics of these two groups were compared. Male patients were significantly

Table 1. Basic clinical and laboratory features of 1238 non-ICU hospitalized COVID-19 patients

\begin{tabular}{|c|c|c|c|c|}
\hline & $\begin{array}{l}\text { Overall cases } \\
(n=1238)\end{array}$ & $\begin{array}{l}\text { Mild-moderate cases } \\
(n=778,62.8 \%)\end{array}$ & $\begin{array}{c}\text { Severe cases } \\
(n=460,37.2 \%)\end{array}$ & $P$ value \\
\hline Ages (years), mean (range) & $54(45-62)$ & $55(32-64)$ & $58(35-68)$ & 0.66 \\
\hline Male, $n(\%)$ & $691(56)$ & $439(56.4)$ & $262(56.9 .8)$ & 0.21 \\
\hline Female, $n(\%)$ & $547(44)$ & $339(43.6)$ & $198(43.1)$ & \\
\hline \multicolumn{5}{|l|}{ Chronic medical illness, $n(\%)$} \\
\hline Hypertension & $280(23)$ & $184(23.7)$ & $96(20.9)$ & 0.51 \\
\hline Diabetes mellitus & $316(25.5)$ & $202(25.9)$ & $114(24.8)$ & 0.39 \\
\hline Chronic heart disease & $178(14)$ & $106(13.6)$ & $72(15.7)$ & 0.18 \\
\hline \multicolumn{5}{|l|}{ Symptom, $n(\%)$} \\
\hline Fever & $946(76.4)$ & $547(70.3)$ & $399(86.7)$ & 0.02 \\
\hline Cough & $928(75)$ & $616(79.2)$ & $312(67.8)$ & 0.32 \\
\hline Expectoration & $687(55.5)$ & $462(59.4)$ & $225(48.9)$ & 0.46 \\
\hline Dyspnea & $759(61.3)$ & $504(64.4)$ & $255(55.4)$ & 0.64 \\
\hline Abdominal pain & $612(49.4)$ & $401(51.5)$ & $211(45.9)$ & 0.34 \\
\hline Nausea/vomiting & $619(50)$ & $385(49.5)$ & $234(50.9)$ & 0.32 \\
\hline Diarrhea & $350(28.2)$ & $196(25.2)$ & $154(33.2)$ & 0.28 \\
\hline Days from disease onset to admission & $9.5(6-12)$ & $8.5(7-12)$ & $7(6-11)$ & 0.12 \\
\hline \multicolumn{5}{|l|}{ Laboratory features on admission } \\
\hline White cell count $\left(4-11 \times 10^{9} / \mathrm{l}\right)$ & $5.8(4.2-13.5)$ & $5.1(4.2-8.6)$ & $9.9(7.6-13.5)$ & 0.03 \\
\hline Lymphocyte count $\left(1.5-4.5 \times 10^{9} / \mathrm{I}\right)$ & $1.3(1.1-2.6)$ & $1.4(1.2-2.6)$ & $1.3(1.1-1.7)$ & 0.18 \\
\hline Total bilirubin (0.3-1 mg/dl) & $1.3(0.8-2.4)$ & $1.2(0.8-1.7)$ & $1.4(1.2-2.4)$ & 0.16 \\
\hline ALT (5-35 IU/I) & $44(24-112)$ & $41(24-58)$ & $56(39-112)$ & 0.14 \\
\hline AST (5-35 IU/I) & $39(18-91)$ & $38(18-66)$ & $50(34-91)$ & 0.21 \\
\hline LDH (70-250 IU/I) & $96(76-246)$ & $88(76-234)$ & $102(82-246)$ & 0.18 \\
\hline Creatinine $(70-150 \mu \mathrm{mol} / \mathrm{l})$ & $72(56-80)$ & $70(56-79)$ & $71(60-80)$ & 0.52 \\
\hline C-reactive protein (< $10 \mathrm{mg} / \mathrm{l})$ & $14(6-86)$ & $13(6-31)$ & $52(19-86)$ & 0.01 \\
\hline $\mathrm{ESR}(\leqslant 20 \mathrm{~mm} / \mathrm{h})$ & $38(20-72)$ & $36(20-54)$ & $48(26-56)$ & 0.11 \\
\hline D-dimer (< $0.5 \mathrm{mg} / \mathrm{l})$ & $0.8(0.5-2.4)$ & $0.9(0.5-1.4)$ & $1.1(0.7-2.4)$ & 0.12 \\
\hline Serum ferritin $(10-200 \mu \mathrm{g} / \mathrm{l})$ & $48(22-232)$ & $52(22-75)$ & $72(48-232)$ & 0.07 \\
\hline
\end{tabular}

ALP - alkaline phosphatase, ALT - alanine transaminase, AST - aspartate aminotransferase, CHD - chronic heart disease, CT - computed tomography, ESR - erythrocyte sedimentation rate, $\gamma$-GT - $\gamma$-glutamyltransferase, $L D H$ - lactic dehydrogenase 
Table 2. Clinical and laboratory features of non-ICU hospitalized COVID-19 patients with and without liver injury

\begin{tabular}{|c|c|c|c|}
\hline & $\begin{array}{c}\text { Patients without } \\
\text { liver injury }(n=942,76.1 \%)\end{array}$ & $\begin{array}{c}\text { Patients with } \\
\text { liver injury }(n=296,23.9 \%)\end{array}$ & $P$ value \\
\hline Ages (years), mean (range) & $51(45.5-65)$ & $59.0(46-62)$ & 0.42 \\
\hline Male, $n(\%)$ & $505(53.6)$ & $186(62.8)$ & 0.03 \\
\hline Female, $n(\%)$ & $437(46.4)$ & $110(37.2)$ & \\
\hline \multicolumn{4}{|l|}{ Chronic medical illness, $n(\%)$} \\
\hline Hypertension & $190(20.2)$ & $92(31.1)$ & 0.78 \\
\hline Diabetes mellitus & $215(22.8)$ & $101(34.1)$ & 0.82 \\
\hline Chronic heart disease & $132(14)$ & $46(15.5)$ & 0.69 \\
\hline \multicolumn{4}{|l|}{ Symptoms, $n(\%)$} \\
\hline Fever & $622(66)$ & $264(89.2)$ & 0.02 \\
\hline Cough & $671(77.1)$ & $218(73.6)$ & 0.73 \\
\hline Expectoration & $453(48.1)$ & $196(66.2)$ & 0.47 \\
\hline Dyspnea & $511(54.2)$ & $208(70.3)$ & 0.31 \\
\hline Abdominal pain & $344(36.5)$ & $231(78)$ & 0.01 \\
\hline Nausea/vomiting & $405(42.9)$ & $178(60.1)$ & 0.42 \\
\hline Diarrhea & $231(24.5)$ & $91(30.7)$ & 0.47 \\
\hline \multicolumn{4}{|l|}{ Lab features on admission } \\
\hline White cell count $\left(4-11 \times 10^{9} / l\right)$ & $4.8(4.2-8.1)$ & $9.3(6.6-13.5)$ & 0.03 \\
\hline Lymphocyte count $\left(1.5-4.5 \times 10^{9} / \mathrm{I}\right)$ & $1.3(1.1-1.8)$ & $1.5(1.2-2.6)$ & 0.13 \\
\hline Total bilirubin (0.3-1 mg/dl) & $0.8(0.5-1.2)$ & $1.7(1.2-2.4)$ & 0.01 \\
\hline ALT (5-35 IU/I) & $36(24-45)$ & $86(58-112)$ & 0.01 \\
\hline AST (5-35 IU/I) & $44(18-51)$ & $73(46-91)$ & 0.01 \\
\hline LDH (70-250 IU/I) & $82(72-116)$ & $94(78-138)$ & 0.21 \\
\hline C-reactive protein $(<10 \mathrm{mg} / \mathrm{l})$ & $14(6-44)$ & $38(22-86)$ & 0.01 \\
\hline $\mathrm{ESR}(\leqslant 20 \mathrm{~mm} / \mathrm{h})$ & $26(20-46)$ & $37(26-56)$ & 0.33 \\
\hline D-dimer $(<0.5 \mathrm{mg} / \mathrm{l})$ & $1.1(0.5-1.8)$ & $1.4(0.6-2.4)$ & 0.11 \\
\hline Serum ferritin $(10-200 \mu \mathrm{g} / \mathrm{l})$ & $63(22-95)$ & $79(45-232)$ & 0.06 \\
\hline Chest CT score & $7(0-10)$ & $13(10-15)$ & 0.01 \\
\hline Length of hospital stay (days) & $9(7-11)$ & $15(12-16)$ & 0.01 \\
\hline
\end{tabular}

ALP - alkaline phosphatase, ALT - alanine transaminase, AST - aspartate aminotransferase, CHD - chronic heart disease, CT - computed tomography, ESR - erythrocyte sedimentation rate, $\gamma$-GT- $\gamma$-glutamyl transpeptidase

more numerous than females in patients with liver injury $(p<0.03)$. Fever and abdominal pain were significantly higher in patients with liver injury $(p<0.02$ and 0.01 respectively). There were significantly higher levels of WBCs, ALT, AST, bilirubin, and CRP levels in the liver injury group when compared to the other group (all $p$ values were $<0.05$ ). The chest CT score of the liver injury group was significantly higher than that of the nonliver injury group $(p<0.01)$. Patients with liver injury had a longer hospital stay than patients without liver injury (15 vs. 9 days respectively, $p<0.01$ ) (Table 2).

Table 3 shows that both ALT and AST correlated significantly with male gender, CRP and D-dimer levels $(p<0.05)$. Chest CT score, as an expression of the sever- ity of COVID-19, was also correlated with ALT and AST ( $r=0.512, p=0.01$ and $r=0.544, p=0.01$ respectively).

Multivariate regression analysis of factors associated with liver injury showed that chest CT score was an independent predictor factor of liver injury after adjusting for male, WBCs, and CRP levels (OR = 5.21, 95\% CI: 1.06-1.39, $p<0.01$ ) (Table 4).

\section{Discussion}

This retrospective multicenter study included 1238 cases with confirmed COVID-19. The most common symptoms were fever (76.4\%), cough (75\%), and dyspnea (61.3\%). Gastrointestinal symptoms were not 
Table 3. Correlation between ALT and AST levels with clinical/laboratory characteristics

\begin{tabular}{lcccc}
\hline & \multicolumn{2}{c}{ ALT level } & \multicolumn{2}{c}{ AST level } \\
\cline { 2 - 5 } & $r$ & $p$ value & $r$ & $p$ value \\
\hline Male gender & -0.363 & 0.01 & -0.251 & 0.04 \\
\hline Age & -0.011 & 0.8 & 0.021 & 0.9 \\
\hline $\begin{array}{l}\text { White blood cell count } \\
\left(4-11 \times 10^{9} \text { cells/l) }\right.\end{array}$ & 0.286 & 0.3 & 0.156 & 0.2 \\
\hline $\begin{array}{l}\text { Lymphocyte count } \\
\left(1.5-4 \times 10^{9} \text { cells/l) }\right.\end{array}$ & -0.04 & 0.7 & -0.24 & 0.08 \\
\hline $\begin{array}{l}\text { C-reactive protein } \\
\text { (< 10 mg/l) }\end{array}$ & 0.316 & 0.01 & 0.466 & 0.001 \\
\hline ESR $(\leqslant 20 \mathrm{~mm} / \mathrm{h})$ & 0.218 & 0.08 & 0.246 & 0.06 \\
\hline D-dimer $(<0.5 \mathrm{mg} / \mathrm{l})$ & 0.326 & 0.02 & 0.288 & 0.03 \\
\hline Chest CT score & 0.512 & 0.001 & 0.544 & 0.001 \\
\hline
\end{tabular}

ALT - alanine transaminase, AST - aspartate aminotransferase, CT - computed tomography, ESR - erythrocyte sedimentation rate, WBC - white blood cells, $C R P-C$ reactive protein. Spearman's rank correlation coefficient was used.

uncommon (abdominal pain 49.4\%, nausea/vomiting $50 \%$, and diarrhea $28.2 \%$ ). Fever, WBC and CRP levels were significantly higher in the severe group (all $p$ values were $<0.05$ ). In our study, we found that nearly $1 / 4$ of non-ICU hospitalized COVID-19 patients (23.9\%) had liver injury and the elevation in ALT, AST and/or bilirubin levels was mild $(\geq 2 \times \mathrm{ULN}$, but $<3 \times$ ULN), suggesting that even in non-critical COVID-19 patients, liver injury was common and benign as all patients improved and were discharged. Males and those who had fever or abdominal pain were significantly more common in the hepatic injury group than the other group $(p<0.05)$. Also, WBCs, CRP and chest CT score showed higher levels in the hepatic injury group $(p<0.05)$. Previous studies reported elevated liver enzymes in a median of $15 \%$ and up to $58 \%$ of patients with COVID-19 with AST and ALT typically elevated 1-2 times the upper limit of normal $[12,13]$. Other studies have found that liver injury was common in critically ill patients with COVID-19 $[4,6,7]$. Huang et al. reported that the median values of ALT and AST in the non-ICU patients were 27 and $34 \mathrm{U} / \mathrm{l}$, respectively, while in ICU patients the median values for both enzymes were higher (49 and $44 \mathrm{U} / \mathrm{l}$ respectively) [7]. Contradicting this, Qingxian et al. reported in their study on 417 COVID-19 patients that more than $76 \%$ of patients had abnormal liver tests at admission $(90 \%$ of them had mild elevation $<2 \times$ ULN, and about $24 \%$ of them developed increased ALT and GGT levels to substantially more than $3 \times$ ULN during hospitalization). They concluded that raised ALT and AST at admission or during hospitalization had significantly higher odds of progressing to severe COVID-19, and the detrimental effects on liver injury were mainly related to the antiviral drugs used during hospitalization, which should be monitored and evaluated frequently [16]. The mechanisms underlying liver injury in COVID-19 patients remain largely uncertain, but many potential etiologies have been postulated, including direct viral infection of hepatocytes, immune-related injury, associated inflammatory responses, congestive hepatopathy, and druginduced liver injury $[17,18,20]$. Angiotensin converting enzyme II (ACE-2) may be a main receptor for the COVID-19 virus, and its expression is upregulated in a mouse model with acute liver injury $[9,10]$. It was reported that the COVID-19 virus may bind to ACE-2 on cholangiocytes, leading to cholangiocyte dysfunction and an inflammatory response leading to liver function abnormalities [19]. To avoid the impact of previous liver disease on our results, we excluded patients with a history of liver disease during the patient enrolment process. None of our patients had received antiviral therapy, so the possibility of drug-induced liver injury can be excluded. Our COVID-19 patients with liver injury had significantly increased WBC and CRP levels, suggesting that the inflammatory process accompanying COVID-19 infection may be the cause of liver function derangement.

The severity of chest CT lesions can reflect the severity of COVID-19. Although it is not confirmed whether there is a causal relationship between the severity of chest CT lesions and liver injury, we noted that patients with liver injury had significantly higher chest

Table 4. Univariate and multivariate regression analysis for factors associated with liver injury

\begin{tabular}{lcccc}
\hline & $\begin{array}{c}\text { Univariate regression analysis } \\
\text { OR, 95\% Cl }\end{array}$ & $\begin{array}{c}P \text { value } \\
\text { Male gender }\end{array}$ & $\begin{array}{c}\text { Multivariate regression analysis } \\
\text { OR, 95\% Cl }\end{array}$ & $P$ value \\
\hline WBC $\left(4-11 \times 10^{9}\right.$ cells/l) & $0.852,0.901-0.982$ & 0.03 & $0.925,0.892-0.911$ & 0.09 \\
\hline CRP $(<10 \mathrm{mg} / \mathrm{l})$ & $1.38,0.223-4.29$ & 0.03 & $1.12,1.78-3.41$ & 0.12 \\
\hline D-dimer $(<0.5 \mathrm{mg} / \mathrm{l})$ & $0.137,1.13-0.72$ & 0.01 & $1.078,1.025-1.13$ & 0.23 \\
\hline Chest CT score & $0.869,0.248-4.73$ & 0.5 & - & 0.01 \\
\hline
\end{tabular}

WBC - white blood cells, CRP - C-reactive protein, OR - odds ratio, $\mathrm{Cl}$ - confidence interval 
CT scores; and chest CT score was a predictor of liver injury, suggesting that patients with severe chest CT lesions need close monitoring of liver function to identify patients with liver damage for early intervention.

In our study, liver injury was mild, no patient needed invasive mechanical ventilation and all patients (with or without liver injury) improved clinically and their nasal swab tests for COVID-19 were negative and patients were discharged safely. These results suggest that liver injury accompanying COVID-19 infection is generally mild, has a good prognosis, and may reflect the severity of COVID-19 infection.

\section{Study limitations}

Although we excluded patients with a history of chronic liver disease or with abdominal sonographic findings of chronic liver disease, we still could not completely rule out chronic liver diseases not known to the patients because our medical resources were limited during the COVID-19 epidemic. However, the levels of liver enzymes in discharging patients with liver injury were normal or near normal, suggesting that their elevation on admission were more likely due to COVID-19 infection than any other underlying liver disease.

\section{Conclusions}

Liver injury in non-ICU hospitalized COVID-19 patients is common but mild and has a good prognosis. Liver injury may be related to the severity of COVID-19 infection. Close monitoring and evaluation of liver enzymes in COVID-19 patients, especially those with severe chest CT lesions, are warranted.

\section{Acknowledgments}

The authors are greatly thankful to all staff members and nurse staff in both Endemic Medicine and Radiology Departments.

\section{Disclosure}

The authors declare no conflict of interest.

\section{References}

1. Centers for Disease Control and Prevention, 2020. Coronavirus disease 2019 (COVID-19) and you. https://www.cdc.gov/ coronavirus/2019-ncov/downloads/2019-ncov-factsheet.pdf (accessed February 27).

2. Morens DM, Daszak P, Taubenberger JK. Escaping pandora's box - another novel coronavirus. N Engl J Med Med 2020; 382: 1293-1295.
3. Zhou P, Yang XL, Wang XG, et al. Discovery of a novel coronavirus associated with the recent pneumonia outbreak in humans and its potential bat origin. Nature 2020; 579: 270-273.

4. Wang D, Hu B, Hu C, et al. Clinical characteristics of 138 hospitalized patients with 2019 novel coronavirus-infected pneumonia in Wuhan, China. JAMA 2020; 323: 1061.

5. Centers for Disease Control and Prevention, 2020. Coronavirus disease 2019. Available at https://www.cdc.gov/coronavirus/2019-ncov/hcp/clinical-guidance-management-patients. html (accessed February 27).

6. Guan W, Ni Z, Hu Y, et al. Clinical characteristics of coronavirus disease 2019 in China. N Engl J Med Med 2020; 382: 1708-1720.

7. Huang C, Wang Y, Li X, et al. Clinical features of patients infected with 2019 novel coronavirus in Wuhan, China. Lancet 2020; 395: 497-506.

8. Li Q, Guan X, Wu P, et al. Early transmission dynamics in Wuhan, China, of novel coronavirus-infected pneumonia. N Engl J Med 2020; 382: 1199-1207.

9. Liang W, Feng Z, Rao S, et al. Diarrhoea may be underestimated: a missing link in 2019 novel coronavirus. Gut 2020; 69: 11411143.

10. Holshue ML, DeBolt C, Lindquist S, et al. First case of 2019 novel coronavirus in the united states. N Engl J Med 2020; 382: 929-936.

11. Gu J, Han B, Wang J. COVID-19: Gastrointestinal manifestations and potential fecal-oral transmission. Gastroenterology 2020; 158: 1518-1519.

12. Sultan S, Altayar O, Siddique SM, et al. AGA Institute rapid review of the gastrointestinal and liver manifestations of COVID-19, meta-analysis of international data, and recommendations for the consultative management of patients with COVID-19. Gastroenterology 2020; 159: 320-334.

13. Clinical best practice advice for hepatology and liver transplant providers during the COVID-19 Pandemic: AASLD expert panel consensus statement, 2020. Available at: https://www.aasld. org/sites/default/files/2020-06/AASLD-COVID19-Expert Panel Consensus State ment-June2 52020-v2-FINAL.pdf (accessed August 4, 2020).

14. https://radiologyassistant.nl/chest/covid-19/corads-classification.

15. Redd WD, Zhou JC, Hathorn KE, et al. Prevalence and characteristics of gastrointestinal symptoms in patients with SARSCoV-2 infection in the United States: a multicenter cohort study. Gastroenterology 2020; 159: 765-767.

16. Cai Q, Huang D, Yu H, et al. COVID-19: Abnormal liver function tests. J Hepatol 2020; 73: 566-574.

17. Jothimani D, Venugopal R, Abedin MF, et al. COVID-19 and liver. J Hepatol 2020; 73: 1231-1240.

18. Schaefer EAK, Arvind A, Bloom PP, et al. Interrelationship between coronavirus infection and liver disease. Clin Liver Dis (Hoboken) 2020; 15: 175-180

19. Chai X, Hu L, Zhang Y, et al. Specific ACE2 expression in cholangiocytes may cause liver damage after 2019-nCoV infection. bio-Rxiv 2020. https://doi.org/10.1101/2020.02.03.931766.

20. Xu L, Liu J, Lu M, et al. Liver injury during highly pathogenic human coronavirus infections. Liver Int 2020; 40: 998-1004. 